\title{
Erratum to "Are Boys More Aggressive than Girls after Playing Violent Computer Games Online? An Insight into an Emotional Stroop Task" [Psychology 5 (2014) 27-31]
}

\author{
Jingjin Tian, Zhang Qian \\ School of Applied Technology, Southwest University, Chongqing, China \\ Email: zhq@swu.edu.cn
}

Received: November 9, 2013

Accepted: December 8, 2013

Published: January 4, 2014

Copyright $\odot 2019$ by author(s) and Scientific Research Publishing Inc. This work is licensed under the Creative Commons Attribution International License (CC BY 4.0).

http://creativecommons.org/licenses/by/4.0/

C) (i) Open Access

The original online version of this article (Tian, J. J., \& Qian, Z. (2014). Are Boys More Aggressive than Girls after Playing Violent Computer Games Online? An Insight into an Emotional Stroop Task. Psychology, 5, 27-31. http://dx.doi.org/10.4236/psych.2014.51006) was published as some results data reported mistakenly. The authors wish to correct the errors to:

\begin{abstract}
The study was to examine the gender differences in aggression among Chinese children after playing violent computer games by using emotional STROOP task. 98 children participated in this study, with 49 assigned to violent computer game group and the other 49 assigned to nonviolent computer game group. The results demonstrated that there are no significant main affect of game type, but a significant Game Type $\times$ Gender interaction was found. In particular, boys' aggression was significantly impacted by violent games, whereas girls' aggression was not significantly impacted by violent games. The implication of this research is that, the significant difference in aggression to gender is activated, and that boys were more aggressive and sensitive to violent games than girls.
\end{abstract}

\subsection{Participants}

98 Chinese children from a primary school from Southwest area participated in the study. Their age was ranged from 12 to $21(\mathrm{M}=16.21, \mathrm{SD}=1.93)$. 


\subsection{Experimental Design}

Multi-factor design was used, with game type and gender as independent variables and aggression as dependent variable. 2 (Game Type: violent vs. non-violent) $\times 2$ (Gender: boy vs. girl) repeated two measures analysis of variance (ANOVA) was conducted with game type and gender as between-group factor, and goal word as within-group factor.

\section{Results}

In this study, we thought the RT of aggressive words was longer than that of nonaggressive words (compared to participants playing nonviolent games). Thus, we assumed each participant had an aggressively priming score (APS), which was RT values by subtracting nonaggressive words from aggressive words and divide by 2 , and examined whether significant difference of APS found in group type.

A two-way analysis of variance (ANOVA) was carried out to examine the main effect of goal word on children' aggression. There was no significant main effect of game type $[F(1,94)=0.81, \mathrm{P}>0.05]$. But we found a significant Game Type $\times$ Gender Interaction $[F(1,94)=7.31, \mathrm{P}<0.01$; see Table 1$]$.

Simple effect analysis showed the average APS of boys playing violent and nonviolent games was significant higher than that of boys playing nonviolent games $[F(1,94)=6.50, P<0.05]$, but no significant APS was found in girls $[F$ $(1,94)=1.62, P>0.05]$. The results can be seen in

ANOVA for Game Type, Game Type $\times$ Gender interaction in APS.

\begin{tabular}{c|c|c|}
\hline Variables & \multicolumn{2}{c|}{ Mean Square F } \\
\hline Game Type & 3202.13 \\
\hline Movie Type $\times$ Gender & $28,814.90$ \\
\hline
\end{tabular}

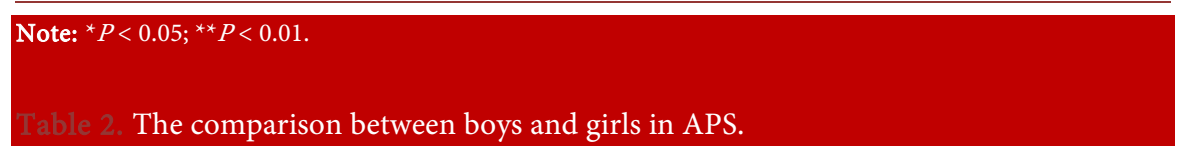

\begin{tabular}{c|c|c|c}
\hline Gender & $\begin{array}{c}\text { Violent Game } \\
\mathrm{M}(\mathrm{SD})\end{array}$ & \multicolumn{2}{c}{$\begin{array}{c}\text { Nonviolent Game F } \\
\mathrm{M}(\mathrm{SD})\end{array}$} \\
\hline Boys & $142.12(12.82)$ & $96.38(12.56)$ & $6.50^{*}$ \\
\hline Girls & $83.16(12.56)$ & $106.02(12.82)$ & 1.62 \\
\hline Note: ${ }^{*} P<0.05$. & & & \\
\hline
\end{tabular}

\section{Discussion}

The study selected Chinese children as participants, which was different from prior researches (Bushman, 1995). In addition, we used emotional Stroop task to explore the gender differences in effects of violent computer games on aggression among children. It was showed that no significant main effect of game type on aggression, but a significant Game Type $\times$ Gender interaction was found, particularly aggression was significantly activated by violent games only among boys, but not among girls. 